\title{
Introduction: Transforming Economic Power to Advance Women's Rights and Justice
}

\author{
CINDY CLARK AND \\ LYDIA ALPÍZAR \\ DURÁN
}

Between 19 and 22 April 2012, close to 2,240 women's rights activists and allies gathered in Istanbul under the banner of Transforming Economic Power to Advance Women's Rights and Justice. In organizing this 12th AWID International Forum on Women's Rights and Development, the intention was to explore how economic power is impacting women and the planet, and facilitate connections among diverse groups to contribute to stronger, more effective strategies to advance women's rights and justice.

In the three years leading up to the Forum, AWID worked with feminist economists and activists to research impacts of the financial crisis and economic recession on women, examine the implications for women of policy responses to the crisis and explore alternative visions of economy and their promise for advancing gender equality. The Forum was an important moment to gather and interrogate much of this analysis and to highlight key dilemmas or areas for further exploration and action in the years ahead.

As Dzodzi Tsikata aptly noted in the final plenary of the Forum, 'Debating development is a cyclical pastime. It's not lack of ideas and alternatives creating underdevelopment, it's the structure of power and decision-making which silences alternative thinking and approaches'.

The Forum itself and the process leading up to (and beyond) organizing it aimed both to surface contributions and insights from feminist economists and activists in key areas of economic analysis and policy (highlights of which are included in this journal), as well as strengthen our mobilization and collective power to transform those structures.

The current world reality challenges women's rights advocates to rethink our frameworks and strategies, renew and reactivate our commitment to movement building, to build up the constituencies that support our agendas, to speak not only to women's rights issues, but also to broader agendas for societal transformation in ways that are compelling to public opinion. In this spirit, the AWID Forum was also a call to revive feminist internationalism, to strengthen efforts of collective organizing across regions and global feminist movement building.

Development (2012) 55(3), 260-263. doi:10.1057/dev.2012.38 


\section{Clark and Alpízar Durán: Introduction}

'Transforming Economic Power'seems a particularly important area of focus given the nature of this historical moment, with enormous changes that are laying bare the fragility (and inadequacy) of the current economic system and the shortcomings of the neo-liberal thinking at its core. The Forum theme aimed to squarely put economic power on the table, push feminists and women's rights movements to engage more head-on with these issues, and build strategies and alternatives for transformation. Even though some women's organizations and networks work on economic issues, the overall engagement of our movements in this area is inadequate. Often women's organizing is focused on survival, but remains isolated and with limited impact on broader macroeconomic questions until clear connections are drawn between core women's rights issues and the economy.

That is why the Forum included ten different sub-themes, to name and deepen analysis of the intersections between economic power and access to and control of resources, militarism conflict and violence, labour and work, sexuality, the role of the state, religion and culture, the planet and ecological health, global governance, financial flows, private sector and corporate power.

At the same time, the complexities and fast pace of change in the current context mean that making these connections and unravelling the economic dimensions shaping women's lives are hardly straightforward tasks. Geopolitical shifts, regionalization processes, perverse incentives that privilege the financial system at the expense of decent jobs and human well-being in times of crisis are just some of the factors that influence how economic policy decisions are being made.

Add to this some of the shifts that are explicitly threatening women's rights; for example, as described by Yakin Erturk, there is an increasing 'culturalization' of women's issues, which creates resistances to women's rights as alien to indigenous cultures, and fragments women's human rights movements. Culturalizing women's rights has delinked women's concerns from unequal gender structures, and from the wider political and economic environment. There are also alarming increases in violence against women human rights defenders, not only in the number of cases, but also in the intensity of the violence being experienced by activists representing social dissent and mobilizing for change. The lack of capacity and resources to deal with this violence represents a clear threat against the sustainability of women's movements and also a clear call to prioritize and understand the political nature of safety, security and self-care, not only at the individual but also at the organizational and movement level, building collective responses to the violence.

It is important to note that the Forum debates were taking place in a region undergoing profound shifts. Women from the Middle East and North Africa brought words of caution from their experiences with the 'Arab Spring' and the extent to which women have been invisibilized after the uprisings, largely excluded from transition processes and now, in many contexts in the region, witnessing the rollback of hard-won achievements for women's rights. Beyond the excitement at the 'possibilities for change' brought by the revolutions in the region, we must now come to grips with some of the realities: protracted conflicts and heightened repression in contexts such as Syria and Yemen, and growing Islamist influence throughout the region. This is important in terms of how we build solidarity with women in the MENA region, as well as the implications of this influence for the global women's rights agenda in spaces such as the UN.

As we enter the period of +20 celebrations Rio, Cairo, Vienna, Copenhagen, Beijing - prospects for significant advances in the full human rights and sustainable development agenda seem bleak.

\section{And what is that transformation?}

The words of Gita Sen during the opening plenary of the Forum stayed with many participants: '[regarding the current economic system] ... are we talking about taking the beast without killing it? I don't think we can kill it, but we need to humanize it'.

Throughout the Forum discussions, there was a tenuous balancing of aspirations for a more just paradigm, a transformed system, while also 
fighting for short-term changes in the current order that could have real and immediate impacts. The macroeconomic framework has not radically altered in the years since the 2008 financial crisis, which many had hoped was the opening of an opportunity for deeper change. Models of economic development still rely predominantly on commodification and growth, positioning the private sector as a key actor and beneficiary, and our global system is fuelled to a great degree by profits derived from militarism, depletion of natural resources and violations of human rights.

What were some of the aspirations named? There was little interest in attempting to identify one single model or even in putting a new adjective in front of development ('sustainable development', 'human development', etc.). Instead, below is a small selection of some of the principles and dimensions that emerged during Forum debates as critical for a more just system of economic power:

- Consider a human rights approach as an ethical lens to judge economic policy; markets and commodification must be in service to human rights and the care and management of the planet; we must reintegrate basic needs and economic rights to human rights discourse.

- Recognition of social provisioning as critical to economic systems and visibility of the diversity of unpaid work on which the commodified economy relies.

- Implement an intercultural approach that evolves the synthesis of values, cultures and visions that are sustainable and desirable as a gift to future generations. Reconnect with and practice the values that underpin non-marketbased economies - reciprocity, collectivity, solidarity, harmony with nature.

- Apply an ecosystem lens - look beyond the dichotomy of individual and collective, beyond a focus on just forest, ocean or air, to consider the whole system and apply this lens to our communities.

- Go beyond existing indicators (like GDP) to claim our own indicators of well-being and sustainability that are responsive to our communities, rooted in the socio-economic condition of each nation. This would require broad and deep discussions across cross-sections of people to unearth the principles and priorities that would guide these indicators.

- We need better tracking and information about the informal economy: not just the romanticized small-scale vendors, but gem, arms, drug trafficking that is responsible for significant volumes of financial flows. These flows have an enormous impact on the broader system.

Bridging diversities and stronger coalition-building was a refrain heard throughout the Forum. This is hardly a new idea, and yet clearly deep alliance-building is a work in progress that remains an urgent task. Some key dimensions of 'bridge-building' stood out as priorities named during the Forum:

- Connections between feminist scholars, economists and activists are key for dialogue across the alternatives taking shape in all those spheres - in the streets and within academia. Such connections are vital to tap the body of work that already exists of solid critical feminist economic analysis, and to bridge gaps between abstract concepts and practical tools, for example, for applying human rights standards to local economic concerns.

- Boaventura de Sousa Santos called for more 'articulation of movements' given that 'no matter how strong a social movement is, it cannot carry out its agenda in isolation'. This call was very much at the heart of the Forum and was why we sought to convene indigenous women, climate justice activists, women working within labour rights movements, economic justice activists, peasants, sex workers, women with disabilities, young women and others, so that from all these diversities participants could identify shared elements of their concerns and agendas as a foundation from which to build stronger understanding and potentially collaboration.

- Weaving insights from the various sites of struggle' in efforts to transform economic power - from trade unions to the UN, from local communities to parliaments, from financial markets to our homes. 


\section{Clark and Alpizar Durán: Introduction}

- In the words of Radhika Balakrishnan, 'globalization requires globalization of resistance'. She called for movement beyond North/South and national divides, for careful work in local contexts but also connecting up regionally and globally. Careful attention to these linkages is vital for transforming economic power.

Building these kinds of bridges requires overcoming the fragmentation and overspecialization that in many cases has weakened or divided feminists and social justice actors. It also requires making visible and acting against the webs of complicity that facilitate the current system; whether it be passive taxpayers financing military interventions around the world, silence in the face of calls for support for economic rights struggles, such as those of sex workers; hypocrisy in the face of labour rights and demands of domestic workers; heightened repression of women human rights defenders.

Beyond the specifics of the learning, experience sharing and passionate debates at the Forum, it is clear that we need to rebuild the strength and power of women's movements at the global level. We need strong movements not just to more effectively confront the serious threats against women's rights and gender equality present in the current context, but also to be proactive and dream big again. The coming three years, with reviews of many key international conferences and frameworks, offer a tremendous opportunity around which to do this rebuilding. It is therefore urgent to overcome differences and build strength from our diverse expressions of organizing, struggles, wisdom and capacity. The task ahead is huge and as history has shown, women need each other and our allies working together in strategic and generous ways, complementing each other's work and drawing power and inspiration from each other's struggles. It is AWID's hope that the 2012 Forum contributed to reenergize and inspire participants to give priority to this process of collective power building across women's movements and struggles at the global level.

Those interested in transforming economic power must be willing to get out of their comfort zones, to learn from others, to build solidarity and to revive that old feminist principle: we are not free, until all women are free, until all people are free. 